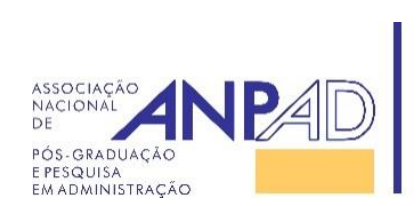

Disponível em

http://rac.anpad.org.br

RAC, Rio de Janeiro, v. 22, n. 5 , setembro/outubro, 2018

http://doi.org/10.1590/1982-7849rac2018180281

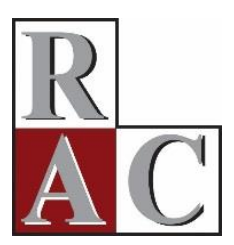

\title{
Editorial:
}

\section{Reconhecimento da Contribuição do Avaliador Anônimo}

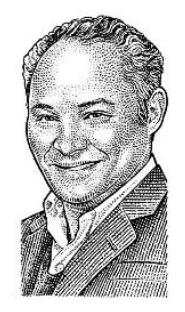

Wesley Mendes-Da-Silva https://orcid.org/0000-0002-5500-4872 Fundação Getulio Vargas, Escola de Administração de Empresas de São Paulo, São Paulo, SP, Brasil

No editorial do número anterior da Revista de Administração Contemporânea (RAC), tratei de transparência e impacto da pesquisa na área de negócios (Mendes-Da-Silva, 2018), enfatizando algo que alguns editores ao redor do mundo têm apontado como relevante para um periódico científico exitoso - a busca por consolidar o caráter ímpar da sua linha editorial (Chen, 1994). A esse respeito, naquela oportunidade, destaquei ainda a relevância, bem como potenciais ganhos compartilhados da abertura dos dados e materiais utilizados nas pesquisas publicadas, como meio de inibir fraudes, permitir a reproducibilidade de resultados, aumentar o interesse da comunidade pelos trabalhos publicados e, ainda, promover a redução de esforços redundantes no trabalho de pesquisa (tal como agências de fomento, como a Coordenação de Aperfeiçoamento de Pessoal de Nível Superior [Capes, 2018] e a Fapesp têm discutido no âmbito brasileiro).

Ainda no mesmo editorial, discuti a relevância do uso de mídias sociais como meio de comunicação de resultados de pesquisa. A RAC, seguindo sua tradição de acompanhar movimentos contemporâneos da comunidade científica, recentemente passou a buscar reportar o nível de impacto dos documentos publicados. Determinadas plataformas concentram-se em certas métricas de altimetria. Para tanto, existe um conjunto diverso de plataformas como: PloS Article Level Metrics, Nature Communications Metrics, Altmetric, Plum Analytics, ScienceCard, PaperCritic, entre outras. Uma das mais proeminentes é a Plum Analytics (Ortega, 2018a), cujo significado central de mensuração encontra-se representado na Figura 1 adiante.

Conforme Dante Cid, Vice-Presidente de Relações Acadêmicas da Elsevier para a América Latina, em palestra proferida durante o encontro denominado Associação Brasileira de Editores Científicos (ABEC), na Universidade de São Paulo, no mês de setembro deste ano de 2018, métricas já impactam não apenas os periódicos, mas também os autores e os artigos. No caso dos autores, o índice $\mathrm{H}$, bem como o número de citações recebidas, são exemplos de indicadores de impacto. Já no nível dos artigos existem métricas emergentes: o número de citações; Field-Weighted Citation Impact 
(FWCI), que leva em consideração a área de conhecimento, permitindo comparabilidade em escala mundial; e, particularmente, nas ciências aplicadas, existe especial preocupação com o impacto social. Isso tem motivado a busca mensuração de impacto para além do número de citações em trabalhos acadêmicos. Nesse sentido, Ortega (2018b), ao comparar três proxies de altmetric, concluiu que não se deve usar apenas um provedor desse tipo de métrica, tendo em vista a existência de diferenças de performance em determinados tópicos.

No presente editorial, trato, principalmente, de um aspecto central para a consolidação de qualquer periódico científico comprometido com a produção de conhecimento de elevada qualidade: o papel dos revisores anônimos. Uma das fundações do sistema de publicação acadêmica é a revisão de manuscritos submetidos ao periódico por parte dos pares. Sem a participação ativa de revisores anônimos voluntários, o sistema de publicações como atualmente conhecemos, corre o risco de colapso (Teixeira da Silva \& Al-Khatib, 2018).

A partir dos princípios de falseabilidade e replicabilidade da ciência, o processo de revisão pelos pares constitui-se no mecanismo de discussão e verificação dos procedimentos metodológicos, bem como dos resultados reportados na pesquisa, como forma de verificar a confiabilidade dos resultados (COPE, 2016). Esse procedimento desempenha o papel de filtro de qualidade, o qual permite identificar os artigos mais relevantes e mais rigorosos, além de possibilitar o controle de artigos fraudulentos, e de limitada reproducibilidade (Ortega, 2017).

Uso: Clicks, downloads, arquivos em bibliotecas, vídeo plays

Capturas: bookmarks, favoritos, arquivamento em ; gerenciadores de referências

Citações: Índices de citação, Citações em patentes, citações clínicas, citações políticas

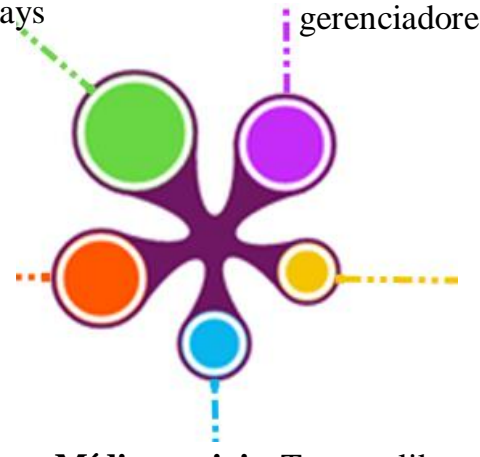

Mídias sociais: Tweets, likes, compartilhamentos
Menções: blog posts, menções, comentários, menções no Wikipédia

Figura 1. Visão Geral do Conceito do PlumX como Altmetria

Plum Analytics fornece insights sobre como as pessoas interagem com documentos de pesquisa (artigos, anais de conferências, capítulos de livros) no ambiente on-line. Exemplos incluem, quando a pesquisa é mencionada nas notícias ou é twittada. Conhecidas como PlumX Metrics, essas métricas são divididas em cinco categorias: uso (e.g., cliques, downloads, visualizações, acervo de bibliotecas, reproduções de vídeo); capturas (e.g., marcadores, favoritos, leitores, observadores); menções (e.g., postagens de blogs, comentários, resenhas, links da Wikipédia, mídia de notícias); mídias sociais (e.g., curtidas, compartilhamentos, tweets); citações (e.g., índices de citações, citações de patentes, citações clínicas, citações de políticas). A altimetria é um ramo da cientometria que mede a influência da produção científica por meio de análises alternativas. Diferente de métricas de citação convencionais, as altmetrics rastreiam impacto para além do meio da comunidade acadêmica, considerando a disseminação do trabalho e o impacto a partir de fontes que não passam pelo processo tradicional de revisão por pares (Barros, M. (2015). Altmetrics: Métricas alternativas de impacto científico com base em redes sociais. (Barros, M. (2015). Altmetrics: Métricas alternativas de impacto científico com base em redes sociais. Perspectivas em Ciência da Informação, 20(2), 19-37. http://doi.org/10.1590/1981-5344/1782)

Um periódico revisado por pares é aquele que submete a maioria de seus artigos publicados para revisão externa. Os revisores, por sua vez, são considerados especialistas em sua área, que avaliam criticamente os manuscritos submetidos para publicação. Os revisores ajudam os editores a decidir se publicam ou não um determinado manuscrito, assegurando que os melhores manuscritos sejam publicados, em paralelo fornecem aos autores um feedback crítico. Em geral, considera-se que a revisão por pares aumenta a qualidade do produto final (Kotsis \& Chung, 2014). Depois de receber a notificação de que um manuscrito requer uma revisão importante, ou mesmo que seu trabalho foi rejeitado sem a oportunidade de revisão (desk reject), os autores podem sentir certo desapontamento e, 
até mesmo, ressentimento. No entanto, as eventuais críticas - que devem sempre ter a cordialidade como característica - não devem ser levadas para o nível pessoal (Provenzale, 2010).

Por outro lado, espera-se que os autores submetam trabalhos que reflitam o melhor de seus esforços, pois qualquer submissão consome importante parcela de recursos, desde as atividades de administração do processo editorial, até especialmente o investimento de tempo alocado pelos revisores voluntários. A revisão por pares está no centro da publicação acadêmica de alta qualidade, e a editoria da RAC será sempre extremamente grata pelo serviço dos revisores anônimos voluntários, os quais, usualmente, examinam cada trabalho submetido a esta revista.

\section{Porque ser revisor anônimo}

O recrutamento de novos e competentes revisores pode estar passando por um momento de estagnação entre as revistas brasileiras na área de negócios. A avaliação por pares, um dos pilares da comunicação científica, enfrenta um momento de transição, em direção à maior confiabilidade, transparência e responsabilidade (Nassi-Calò, 2017). Ser convidado a revisar um manuscrito é uma responsabilidade que todos os revisores devem honrar. É claro que os comentários dos revisores são benéficos para os autores, mas a revisão também pode ser benéfica para o revisor, melhorando as habilidades de pensamento crítico (Kotsis \& Chung, 2014). Ao mesmo tempo, deve-se considerar que os revisores podem ter motivos para, frequentemente, sentirem-se superocupados e sub-remunerados, no caso particular da RAC, os revisores não recebem qualquer tipo de compensação financeira pelo seu trabalho voluntário.

Não é tarefa fácil e mecânica encontrar revisores motivados e engajados o suficiente para realizar revisões de excelência explícita, merece destaque a frequência com que convites para realizar pareces são declinados por revisores tecnicamente mais indicados para realizar pareceres, e até mesmo pesquisadores menos experientes não têm aceitado tão frequentemente a missão de realizar pareces. Isto se reflete na duração do processo editorial, já que é necessário recorrer a um número de convites acima daquilo que poderia ser o suficiente para fazer com que o julgamento de trabalhos submetidos ocorra sem maiores sobressaltos. A carência de incentivos para desempenhar o papel de revisor é um fator que limita o número de pesquisadores na área de negócios dispostos nessa função. Conforme Cuellar (2018), sem que haja uma plataforma estruturada para reconhecer e incentivar pesquisadores, os periódicos continuarão a experimentar elevada dificuldade para manter a qualidade e a celeridade desejadas no processo editorial. As bases dessa visão são compartilhadas por outros pesquisadores (Bianchi, Grimaldo, Bravo, \& Squazzoni, 2018; Lundstrom \& Baker, 2009; Verbeke, Von Glinow, \& Luo, 2017). Para além das questões relativas ao incentivo a revisores, cabe realçar o princípio da reciprocidade acadêmica (Chang, 2001).

\section{Reciprocidade acadêmica}

De acordo com Chang (2001), há puzzles no julgamento de artigos científicos: Por que os indivíduos estariam dispostos a revisar um artigo sem que recebam pagamento pelo seu trabalho, e vale a pena pagar aos revisores para aumentar a disposição a revisar trabalhos? Chang (2001) aponta dois resultados principais: primeiro, quando o serviço de revisão é orientado pela reciprocidade, a participação dos revisores pode desempenhar um papel de auto realização. Em segundo lugar, o pagamento ótimo pode não ser zero, se o árbitro receber o benefício da reputação obtida ao julgar um manuscrito candidato à publicação. Chang (2001) defende que os periódicos cuja taxa de revisão é menor, tendem a pagar mais aos revisores, enquanto os periódicos cuja taxa de revisão é mais alta não acham que vale a pena pagar o suficiente aos revisores.

Revisar artigos para um periódico é visto como uma atividade recíproca entre os membros da comunidade acadêmica. A revisão de manuscritos para um periódico é vista como uma atividade recíproca entre todos os avaliadores. A reciprocidade acadêmica é um 
tema que tem sido estudado no nível teórico. A esse respeito, Chang (2001) formaliza a interação entre o editor de um periódico científico e potenciais avaliadores de manuscritos. Em geral, avaliadores têm a opção de declinar do convite para revisar trabalhos, o quê não é raro. Quando um avaliador não se dispõe a revisor um manuscrito, o trabalho retorna para o editor. Em consequência, custos de atraso acabam sendo impostos sobre o periódico, por meio de uma soma fixa de valor $\delta$. Nesse contexto, o editor necessita continuar a sua busca por revisores para o dado trabalho submetido. Assim, o custo total esperado de atraso, $D$, pode ser representado por (1):

$$
D=(1-\mu)(\delta+D)
$$

onde $\mu$ é a proporção de avaliadores que optam por revisar o trabalho. A partir de (1), Chang (2001) deriva (2):

$$
D=\frac{1-\mu}{\mu} \delta=\left(\frac{1}{\mu}-1\right) \delta
$$

Por outro lado, do ponto de vista de um revisor, ele recebe uma recompensa $w$, mas incorre em custos $c$ se estiver disposto a revisar o artigo. Sem perda de generalidade, assumese que $c$ indica uma distribuição uniforme, $f(c)$, no intervalo $[0,1]$, e a sua função de densidade acumulativa é $F(c)=C$. A reputação acadêmica do revisor pode se beneficiar quando o revisor avalia um artigo para um periódico de alta qualidade. Este efeito benéfico é evidenciado por dois fatos. Primeiro, todos os anos, a maioria dos periódicos publica a nominata de revisores, i.e. uma lista de todos os revisores, com a intenção expressar seu agradecimento por seus serviços. Segundo, a maioria dos acadêmicos selecionará alguns periódicos estabelecidos nos quais eles serviram como árbitros e os listará em seu currículo. De acordo com Laband (1990), se a taxa de participação dos revisores for alta, o processo de revisão poderá atuar não apenas como um bom mecanismo de triagem, mas também fornecerá valor agregado ao paper e, consequentemente, melhorará a qualidade da revista. Quanto maior a qualidade da revista, mais benefícios de reputação o revisor anônimo poderá obter.

Em essência, os periódicos mais bem-sucedidos são mais atraentes para trabalhar e, portanto, encontram menor dificuldade em recrutar revisores e manter sua vantagem, enquanto os menos bem-sucedidos têm mais dificuldade em recrutar revisores e, portanto, permanecem menos exitosos. Em adição, do ponto de vista do editor, o pagamento ótimo para o revisor pode não ser zero. $\mathrm{Na}$ realidade, os editores de fato tentam realizar aos revisores alguns pagamentos implícitos para encorajar revisões de artigos para seus periódicos e esperam que isso diminua os custos de atraso. Postas essas questões práticas e teóricas a respeito da atuação de pesquisadores como revisores anônimos resta ao menos uma questão: se mais cientistas estão de fato se esquivando de suas responsabilidades de revisão por pares, o que pode ser feito para corrigir a situação? Uma opção poderia ser proporcionar aos pesquisadores, instituições de pesquisa, e à comunidade científica de modo geral, incentivos para revisar artigos. É exatamente isso que os criadores do Publons alegam ter em mente, conforme destacam Rajpert-De Meyts, Losito e Carrell (2016).

\section{Publons}

Smith (2016) descreve seu sentimento de culpa originado pelo descumprimento de prazos para emitir pareces solicitados por editores de revistas científicas. No mesmo texto, Smith (2016) aponta o Publons como meio de dirimir esse sentimento. Fundado em 2013, o Publons é um serviço de mídia social on-line gratuito que permite aos usuários gravar, compartilhar e exibir suas atividades de revisão por pares. Conforme Cuellar (2018), o 
Publons atualmente é a plataforma que lidera, no âmbito mundial, o registro de atuação de revisão pelos pares, com a finalidade de reconhecer oficialmente as contribuições dos revisores.

A platforma do Publons conta atualmente algo em torno de 250.000 revisores no seu banco de dados, com mais de 1,4 milhão de resenhas reportadas e fez parcerias com 1.650 periódicos e 42 editoras. O Publons promete manter o histórico de revisões que avaliadores realizem para determinados periódicos, inclusive a RAC. Publons permite-nos fornecer aos revisores o reconhecimento que é vital para o desenvolvimento e a integridade da disseminação da ciência (Nassi-Calò, 2017). Essa plataforma pode fornecer aos revisores um reconhecimento em um local centralizado. O Publons pode ser sincronizado com outras plataformas, como a ORCID ou páginas da web. O Publons verifica ainda se as revisões são autênticas e confiáveis (Cuellar, 2018).

Como outras plataformas de mídia social acadêmica, como o ResearchGate, o Publons fornece aos seus membros várias métricas acadêmicas e uma pontuação geral, que podem ser usadas para comparar-se com outros membros, e candidatar-se a concorrer a financiamento de pesquisas por agências de fomento internacionais por exemplo. Mas ao contrário da ResearchGate, a Publons não recompensa seus usuários pelo número e impacto de artigos publicados; em vez disso, classifica os usuários (e as instituições) com base no número de artigos revisados por pares (Smith, 2016). O Publons pode ser usado como incentivo ou recompensa para a contribuição como revisor a um periódico. Para mais informações sobre Publons, ou para inscrever-se (gratuitamente), visite https://publons.com.

\section{Recomendações para fazer um bom parecer}

Entre os periódicos de largo alcance internacional, a preocupação com a qualidade das revisões realizadas pelos pares é algo em destaque (Staniland, 2016). Não é raro encontrar na literatura análises do impacto da qualidade das revisões sobre a qualidade dos periódicos (Black, Van Rooyen, Godlee, Smith, \& Evans,1998; Drummond \& Jefferson, 1996; Fielden, 2008; Kotsis \& Chung, 2014). Na Tabela 1 adiante, apresento um conjunto de aconselhamentos para os indivíduos preocupados em manter a qualidade ou melhorar o padrão de seu serviço voluntário, a título de reciprocidade acadêmica no processo de julgamento pelos pares.

Tabela 1

Dicas para Emitir um Bom Parecer para Trabalhos Submetidos

\begin{tabular}{ll}
\hline O que fazer & Qual a consequência desse comportamento \\
\hline Responda prontamente a convites & $\begin{array}{l}\text { Quando você receber um convite para revisão, tente responder } \\
\text { prontamente, ou então você pode atrasar o processo editorial. O } \\
\text { resumo do artigo pode ser útil para você decidir se o manuscrito } \\
\text { está em sua área de interesse e experiência. }\end{array}$ \\
\hline Mostre Integridade & $\begin{array}{l}\text { Mantenha o conteúdo de qualquer manuscrito que você esteja } \\
\text { revisando como confidencial. Você esperaria o mesmo dos outros } \\
\text { revendo seu próprio trabalho. Além disso, se você enviou uma } \\
\text { pesquisa semelhante ou se revisou o artigo para um periódico } \\
\text { diferente, informe ao editor que há um conflito de interesses. } \\
\text { Concordar com uma revisão para obter ganhos pessoais não é } \\
\text { apropriado. }\end{array}$ \\
\hline
\end{tabular}


Tabela 1 (continuação)

\begin{tabular}{|c|c|}
\hline O que fazer & Qual a consequência desse comportamento \\
\hline Permaneça dentro do escopo & $\begin{array}{l}\text { Ao comentar, certifique-se de que suas observações permaneçam } \\
\text { dentro do escopo do artigo e não desviem do assunto. Se você não } \\
\text { souber o escopo, a política editorial, os requisitos de apresentação e } \\
\text { envio, fale com o editor ou leia as Orientações aos autores. }\end{array}$ \\
\hline Seja construtivo & $\begin{array}{l}\text { Seu comentário deve ajudar o autor a melhorar o artigo. Portanto, } \\
\text { certifique-se de oferecer um feedback construtivo, mesmo que sua } \\
\text { recomendação acabe sendo rejeitada. }\end{array}$ \\
\hline Aloque tempo suficiente & $\begin{array}{l}\text { Analisar e comentar cuidadosamente um manuscrito pode levar um } \\
\text { bom tempo. Certifique-se de ter tempo suficiente disponível ao } \\
\text { fazer uma revisão. }\end{array}$ \\
\hline Seja consistente & $\begin{array}{l}\text { Estruture seus comentários, numerando-os. Isso torna a vida do } \\
\text { editor muito mais fácil. Você também pode dividi-los em questões } \\
\text { maiores e menores para ajudar os autores a priorizar as correções. } \\
\text { Mantenha os comentários dos autores separados dos confidenciais } \\
\text { para os editores. Mas certifique-se de que seus comentários aos } \\
\text { autores correspondam à sua avaliação na revisão confidencial e nas } \\
\text { listas de verificação. }\end{array}$ \\
\hline Concentre-se na pesquisa & $\begin{array}{l}\text { Se você está revisando um artigo em inglês ou em espanhol, mas } \\
\text { não foi escrito por um indivíduo nativo, é adequado ser tolerante e } \\
\text { apontar elementos que mudam o significado, em vez de comentar } \\
\text { sobre a qualidade do inglês. }\end{array}$ \\
\hline Verifique a conclusão primeiro & $\begin{array}{l}\text { A conclusão lhe dará uma boa ideia se a pesquisa representa uma } \\
\text { contribuição para o seu próprio campo. }\end{array}$ \\
\hline Verifique a robustez dos fatos & $\begin{array}{l}\text { Os editores percebem quanto útil é se você comentar sobre o } \\
\text { número de repetições, controles e análises estatísticas. Estatísticas } \\
\text { fortes são cruciais para determinar se o resultado é robusto. }\end{array}$ \\
\hline Dar crédito aos pontos positivos é devido & $\begin{array}{l}\text { Se um artigo que você está revisando for realmente bom e uma } \\
\text { excelente contribuição à literatura existente, não tenha medo de } \\
\text { dizer isso. }\end{array}$ \\
\hline
\end{tabular}

Ao mesmo tempo em que existem atitudes desejáveis e esperadas por parte dos indivíduos participantes da comunidade de pesquisadores em negócios, vale atribuir ênfase a atitudes que devem ser evitadas no mesmo ambiente.

\section{Atitudes a serem evitadas por um bom revisor}

Blocken (2017) aponta dicas ao redor de comportamentos a serem evitados pelos revisores. Na Tabela 2 segue uma lista não exaustiva de comportamentos a evitar quando no exercício do juízo de valor é inadequado papel de revisor de trabalhos submetidos a periódicos científicos. 
Tabela 2

\section{Dicas sobre o que Não Fazer na Emissão de Parecer para Trabalhos Submetidos}

\begin{tabular}{|c|c|}
\hline O que não fazer & Qual a consequência desse comportamento \\
\hline $\begin{array}{l}\text { Aceitar um convite para } \\
\text { revisar quando você } \\
\text { não deveria. }\end{array}$ & $\begin{array}{l}\text { Se você respeitar a reciprocidade acadêmica, estará disposto a aceitar convites para revisar } \\
\text { trabalhos, certamente de periódicos nos quais você publicou, ou para os quais deseja enviar } \\
\text { seu próprio trabalho no futuro. No entanto, não aceite um convite de revisão quando você } \\
\text { nunca tiver experimentado o processo de revisão por pares na condição de autor. Não aceite } \\
\text { revisar artigos sobre um tópico que não corresponda à sua área de especialidade, ou quando } \\
\text { você tiver um conflito de interesses. Se você concordou muito rápido e perceber esses } \\
\text { problemas somente depois de aceitar a redação, não se preocupe. Notifique o editor em vez } \\
\text { de entregar uma revisão pobre. }\end{array}$ \\
\hline
\end{tabular}

Enviar sua opinião muito tarde, ou sequer enviá-la.
A reciprocidade é, frequentemente, mas nem sempre, integralmente aconselhada. Se você tiver experimentado espera por uma revisão (muito) atrasada como autor, não replique esse mesmo tratamento, quando estiver atuando como revisor. Infelizmente, isso acontece com alguma frequência e pode surgir um círculo vicioso que é muito prejudicial para a revista e para a comunidade de pesquisadores. A pior opção é aceitar o convite, mas nunca enviar o seu comentário. Atrasa todo o processo porque faz com que o editor convide novos revisores. Isso também aumenta a carga de trabalho dos colegas que agora precisam fazer a revisão que você deveria ter feito. Se o seu sonho é personificar o pesadelo do editor: então, esse conselho vai para você.

Ignorar as mensagens do editor

Se você fizer uma boa revisão a tempo, provavelmente só receberá mensagens automáticas. Em outros casos, o editor pode entrar em contato com você pessoalmente. $\mathrm{O}$ editor pode acabar pedindo para que você informe o status (caso o trabalho de revisão esteja atrasado), ou mesmo informações adicionais (caso sua avaliação não esteja clara ou completa o suficiente). Não responder a uma pergunta é considerado bastante indelicado na rotina diária do processo editorial. Se você quiser dar ao editor linguagem conotativa Ironia é uma figura de linguagem inadequada nesse gênero.

Não verificar a aderência à ética de publicação A ética da publicação contém muitos elementos. Plágio, por exemplo, é uma violação grave. Como a pressão de publicação contínua e crescente, as tentativas de plágio têm se tornado mais frequentes. Embora a maioria dos editores acadêmicos tenha instalado procedimentos muito elaborados para detectar o plágio, como o Crossref Similarity Check, provavelmente o melhor instrumento de detecção para o plágio no campo de pesquisa seja o próprio revisor anônimo: aquele que conhece a literatura e o estado da arte no campo de conhecimento. Às vezes, os problemas podem ser resolvidos lembrando aos autores que eles devem adicionar as referências apropriadas nos locais apropriados para indicar que algumas declarações e descobertas não são deles, mas devem ser atribuídas a outras pessoas. Os revisores devem indicar claramente ao editor quando encontrarem conteúdo aparentemente plagiado, o que evidentemente inclui reivindicar o reconhecimento de ideias oriundas de outros autores.

Fornecer uma revisão pouco útil

Então, você aceitou o convite para revisar um trabalho, mas o prazo está se aproximando, e você tem mais coisas a fazer do que revisar trabalho dos outros. Isso acontece com todos nós. Quando isso acontece, pode ser tentador apenas navegar pelo artigo e escrever algumas linhas gerais e vagas que são absolutamente inúteis para o editor e os autores. Isso não é apenas desrespeito ao trabalho do autor, mas também exige que o editor convide novos revisores, o que aumentará a carga para os outros e atrasará todo o processo. Você também prejudicará diretamente sua reputação: seus conselhos (aceitar/revisar/rejeitar) podem estar em contraste direto com o parecer emitido por outros revisores. Mas, mesmo sem isso, o editor não considerará mais suas revisões com seriedade e poderá deixar de convidá-lo no futuro. Não há benefício sem doação. A lei da reciprocidade implica que você não pode esperar que os outros continuem fornecendo revisões úteis para seus próprios manuscritos submetidos, se você não se dispuser a retribuir o favor. Talvez você pense que só causará uma má impressão a esse único editor, mas a questão pode muito bem ser compartilhada com o corpo editorial. Se você não se importa tanto com sua reputação acadêmica e não se importa em causar frustração a editores e autores, essa dica pode economizar muito tempo. 


\section{Tabela 2 (continuação)}

\begin{tabular}{ll}
\hline O que não fazer & Qual a consequência desse comportamento \\
\hline $\begin{array}{l}\text { Esquecer de abordar os } \\
\text { principais componentes }\end{array}$ & Adiante vão perguntas a respeito dos principais componentes de um artigo que os \\
do artigo & - O artigo se encaixa no escopo da revista? \\
& - Qual a novidade da pesquisa? \\
& - O título é representante do conteúdo e do principal resultado do artigo? \\
& - O resumo reflete o conteúdo claramente? \\
& - O estado da arte está bem descrito e a lacuna de conhecimento está claramente \\
& definida? \\
& - Os objetivos são bem articulados? \\
& - O método aplicado na pesquisa é sólido? \\
& - Os resultados são confiáveis e os objetivos alcançados? \\
& - As limitações são mencionadas corretamente? \\
& - As conclusões são justificadas? \\
Se necessário, forneça recomendações aos autores sobre como melhorar esses \\
componentes. Além disso, Esses elementos estão evidentes nesse texto, contudo, não \\
sei se esse era o objetivo do autor.
\end{tabular}

Fornecer declarações pouco claras, injustas, ou mesmo tendenciosas
Bons ingredientes para uma crítica verdadeiramente terrível são declarações pouco claras, injustas e tendenciosas. Seus comentários e recomendações devem ser claros e inequívocos. Declarações como "a metodologia não é sólida" ou "as conclusões são injustificadas" não têm valor em si. Críticas e sugestões esclarecedoras são importantes, pois editores e autores não podem ler sua mente; eles só podem ler seu comentário. Não apenas declare o que deve ser melhorado, mas também sugira como ele pode ser melhorado. Evite declarações desdenhosas, injustas e tendenciosas. Você teria feito um trabalho muito melhor e mais completo do que os autores, certo? Pense novamente. Em geral, é mais fácil identificar deficiências no trabalho dos outros do que no seu. Isso não significa que seu trabalho seja melhor; significa tão somente que você também precisará de revisores que forneçam comentários claros, imparciais que apontem para as deficiências identificadas em seu próprio trabalho. Você deve ser grato por isso e deve certificar-se de que os autores serão gratos a você. Nenhuma pesquisa é perfeita, e toda publicação, não importa a área ou tópico da pesquisa é, na melhor das hipóteses, um elo muito pequeno na longa cadeia de avanço incremental do conhecimento em um minúsculo subcampo da ciência. A modéstia adapta-se bem aos autores, e o mesmo vale para os revisores.

Impedir injustamente a publicação ou violar a confidencialidade
Se você quiser ter certeza de nunca mais receber um convite de revisão de um determinado periódico, preste muita atenção a esta dica. É altamente improvável que você ou seus colegas de trabalho sejam os únicos no planeta Terra trabalhando em um tópico específico em um campo específico. Se outras pessoas estiverem trabalhando no mesmo tópico, é bem provável que você seja convidado a revisar o artigo. E se você acabou de enviar um artigo sobre esse assunto para outro periódico ou está preparando um artigo? A violação mais grave da ética do revisor seria obstruir injustamente a publicação do trabalho do autor e/ou usar seu conhecimento do trabalho para obter vantagem competitiva. Menos grave, mas ainda muito antiético, é violar a confidencialidade compartilhando o conteúdo da submissão com outros antes da publicação. Se você não puder fazer uma revisão justa, rápida e construtiva - o que é certo - então você deve declarar imediatamente um conflito de interesse e notificar o editor. Honestidade e virtude sempre superam o avanço pessoal e a fama temporária. 


\section{Tabela 2 (continuação)}

\begin{tabular}{ll}
\hline O que não fazer & Qual a consequência desse comportamento \\
\hline $\begin{array}{l}\text { Sugerir que os autores } \\
\text { violem regras de ética }\end{array}$ & $\begin{array}{l}\text { Como revisor, você tem algum poder. Use-o de maneira justa, sábia e moderada, } \\
\text { na pesquisa }\end{array}$ \\
& $\begin{array}{l}\text { sempre com o intuito de apoiar a RAC, bem como o seu campo de pesquisa. Não peça } \\
\text { sobre o trabalho de outras pessoas. Não peça aos autores para adicionar citações que }\end{array}$ \\
& não são relevantes, i.e. não peça que os autores adicionem citações irrelevantes \\
& intencionando inflar o número de citações de seus próprios papers e consequentemente \\
& seu próprio índice h. Se você não gosta de revisar trabalhos submetidos, se você quer \\
& desapontar completamente o editor, ou se você quer ter certeza de que ele nunca mais o \\
& convidará, este conselho é para você.
\end{tabular}

Esquecer de rever os

Finalmente, com ou sem as dicas anteriormente mencionadas, você chegou ao estágio seus comentários com a em que sua revisão está pronta. Certo? Não, na verdade não. Não é improvável que regra de ouro você tenha escrito algo que você vai se arrepender depois, ao ler seu comentário novamente. Portanto, certifique-se de reler seu parecer antes de enviá-la à RAC. Neste estágio, em particular, aplique a regra de ouro: não faça com autores aquilo que você não gostaria de receber dos outros revisores. Examine a revisão e remova as declarações potencialmente severas ou ofensivas. Reformule comentários possivelmente pouco claros, injustos ou tendenciosos. Acima de tudo: seja educado, justo e gentil. Se você recomendar a revisão do manuscrito, faça-o gentilmente. Se possível, encerre suas críticas adicionando um elogio ou dois. Mesmo se você tiver que recomendar a rejeição do manuscrito, faça-o gentil e educadamente. Os autores se sentirão mal neste caso, não há necessidade de piorar as coisas.

Entre comportamentos a serem evitados, e outros condutas vistas como desejáveis em um revisor, além da escassez de indivíduos suficientemente qualificados e minimamente abnegados para desempenhar o papel de revisor voluntário; a literatura documenta iniciativas que podem contribuir para o surgimento de novos bons revisores, além de melhorar as habilidades dos revisores em atuação (Callaham, Green, \& Houry, 2012; Callaham, Knopp, \& Gallagher, 2002; Callaham \& Tercier, 2007; Callaham, Wears, \& Waeckerle, 1998).

\section{Palavras Finais}

O trabalho do revisor é indispensável ao funcionamento das revistas científicas, todos devemos reciprocidade aos demais colegas da comunidade acadêmica. Contudo, encontrar avaliadores dispostos a doar seu tempo para ler e avaliar trabalhos alheios é algo caro ao editor e ao periódico. Por isso, nesta edição, publicamos a Nominata dos Avaliadores que atuaram em 2017, ao mesmo tempo em que parabenizamos o Professor Valter Afonso Vieira (UEM, Paraná, Brasil), que durante o EnAnpad 2018 recebeu a distinção de melhor avaliador de periódicos da Anpad. Cabe reconhecer, portanto que, graças ao trabalho sério desenvolvido por essas pessoas, a RAC tem sido capaz de cumprir seu papel de entregar à sociedade brasileira conhecimento de qualidade no campo da administração.

Silvio Popadiuk, que atua na Universidade Presbiteriana Mackenzie em São Paulo, Aruana Rosa Souza Luz e Caroline Kretschmer da Universidade do Vale do Rio dos Sinos contribuíram nesta edição da RAC com o artigo intitulado Dynamic Capabilities and Ambidexterity: How Are These Concepts Related? Com esse trabalho, os autores buscam investigar trabalhos anteriores sobre teorias de estratégia e organizações que discutem a 
relação ambidestria-capacidades dinâmicas mediante uma revisão sistemática da literatura complementada por uma técnica de "bola de neve".

Dois dos seis artigos desta edição são oriundos da região Nordeste do Brasil. Lógica de Mercado como Medida de Eficiência da Organização do Carnaval de Olinda, de autoria de Suélen Matozo Franco, e de André Luiz Maranhão de Souza Leão investiga como a lógica do mercado é adotada no Carnaval de Olinda, tomando como base a Análise do Discurso sistematizada por Foucault. Para tanto, esses autores debruçaram-se sobre dados relativos a toda a cobertura jornalística dos carnavais de 1986, 1996, 2006 e 2016 presentes nos dois principais jornais de maior circulação em Pernambuco. Já o trabalho intitulado Efetividade do Crowdsourcing como Apoio à Segurança Pública, produzido por João Moisés Brito Mota e Afonso Carneiro Lima, apoia-se no método Delphi para constatar ausência de políticas estratégicas de longo prazo e a existência de obstáculos institucionais para o pleno aproveitamento de novas tecnologias na esfera da segurança pública, analisando dados oriundos do Ceará.

O quarto artigo vem da região Sul do Brasil, Integração Vertical em Montadoras Automotivas, de autoria de Cleiciele Albuquerque Augusto, José Paulo de Souza, e Silvio Antonio Ferraz Cario, a partir de dados da indústria automobilística no Paraná, tem como objetivo compreender a escolha da integração vertical em montadoras de veículos automotivos, considerando a presença de custos de transação, de mensuração e de recursos estratégicos.

O quinto artigo, intitulado Desenvolvimento de um Framework de Adoção da Inovação no Mercado de Baixa Renda, de autoria de Vitor Koki da Costa Nogami e Andres Rodriguez Veloso, concentra-se em apresentar o desenvolvimento de um framework de adoção da inovação do consumidor de baixa renda, enfatizando principalmente os consumidores e suas restrições estruturais e individuais, encontradas no contexto de pobreza. O sexto e último artigo é decorrente de convite formulado a Anete Alberton (que deixa, nesta oportunidade, a editoria de Casos de Ensino da RAC, após anos de dedicação exemplar), e Anielson Barbosa da Silva (atualmente membro do Conselho Editorial da RAC): Como Escrever um Bom Caso para Ensino? Reflexões sobre o Método. O convite a essas duas pessoas foi decorrente de suas atuações continuadas na construção e na aplicação de casos de ensino.

Completam esta edição da RAC um artigo tecnológico e dois casos de ensino. O artigo tecnológico vem do Sudeste do Brasil, de Minas Gerais, Riscos e Possível Solução Associados às Amostras em Redes de Coautoria, de autoria de Uajara Pessoa Araujo, Fabrício Molica de Mendonça, Rita de Cássia Leal Campos e de Lara Figueiredo e Silva. Os dois casos de ensino também vêm da região Sudeste do Brasil: Team Nogueira: Invasão do Mixed Martial Arts no Universo Fitness, de autoria de Rafaela Barbosa Ferreira dos Santos, João Guilherme Barbosa de Amorim, Flavia d`Albergaria Freitas e Victor Manoel Cunha de Almeida, é oriundo do Rio de Janeiro; e Desafios no Desenvolvimento de um Serviço Publicitário Baseado em Big Data, de autoria de Kenyth Alves de Freitas, e Luiz Di Serio vem de São Paulo.

Por fim, eu devo realçar, neste editorial, o empenho da Diretoria da Anpad no sentido de permitir o desenvolvimento da Revista de Administração Contemporânea, tendo em vista tratar-se de um periódico de referência. Nos últimos meses foram envidados esforços por parte desta editoria, e por parte da Anpad, para que o padrão de apresentação do website da RAC, bem como dos próprios documentos publicados por este periódico, passassem a assumir um novo formato que permita funcionalidades adicionais, além de melhorar a comunicação da 
RAC com indexadores almejados em um futuro próximo. Esta editoria ressalta, ainda, o empenho na manutenção da transparência e dos padrões éticos adotados nos trabalhos editoriais. Como consequência, estimulamos o compartilhamento de $\operatorname{dados}^{(1)}$ e materiais (COPE, 2018; Mendes-Da-Silva, 2018) e a inclusão de mais revisores comprometidos com o desenvolvimento da comunidade de negócios, via reciprocidade acadêmica.

Boa leitura!

\section{Indicadores do Processo Editorial da RAC (janela móvel maio/2017 a maio/2018)}

\begin{tabular}{lll}
\hline Situação & Jun2017-Mai2018 & Mai2017-Abr2018 \\
\hline Total de artigos publicados & 35 & 42 \\
Total de artigos submetidos & 440 & 319 \\
Artigos em avaliação & 56 & 55 \\
Artigos aceitos e publicados & 26 & 18 \\
Artigos aceitos a serem publicados & 06 & 04 \\
Tempo médio entre submissão e publicação (\# dias) & 298 & 315 \\
\hline
\end{tabular}

\section{Nota}

${ }^{1}$ Conforme o Committee on Publication Ethics (COPE, 2016), os periódicos devem incluir políticas acerca da disponibilidade de dados, e também devem encorajar o uso de relatórios que detalhem os procedimentos metodológicos empregados na condução da pesquisa. Desde a edição 22.4 2018, a RAC adota política de compartilhamento de dados e materiais, em atendimento ao que preconiza o item 10 dos Princípios de Transparência e Melhores Práticas de Publicação Acadêmica do COPE (2018). Para mais detalhes recomenda-se ver https://publicationethics.org/data.

\section{Referências}

Barros, M. (2015). Altmetrics: Métricas alternativas de impacto científico com base em redes sociais. Perspectivas em Ciência da Informação, 20(2), 19-37. http://doi.org/10.1590/1981-5344/1782

Bianchi, F., Grimaldo, F., Bravo, G., \& Squazzoni, F. (2018). The peer review game: An agent-based model of scientists facing resource constraints and institutional pressures. Scientometrics, 116(3), 1401-1420. https://doi.org/10.1007/s11192-018-2825-4

Black, N., Van Rooyen, S., Godlee, F., Smith, R., \& Evans, S. (1998). What makes a good reviewer and a good review for a general medical journal?. Journal of the American Medical Association, 280(3), 231-233. https://doi.org/10.1001/jama.280.3.231

Blocken, B. (2017, September 12). Ten tips for a truly terrible peer review. Retrieved from https://www.elsevier.com/connect/reviewers-update/ten-tips-for-a-truly-terrible-peer-review

Callaham, M. L., Green, S., \& Houry, D., (2012). Does mentoring new peer reviewers improve review quality? A randomized trial. BMC Medical Education, 12(83). https://doi.org/10.1186/14726920-12-83. 
Callaham, M. L., Knopp, R. K., \& Gallagher, E.J. (2002). Effect of written feedback by editors on quality of reviews: Two randomized trials. JAMA 287(21):2781-2783. https://doi.org/10.1001/jama.287.21.2781

Callaham, M. L., \& Tercier, J. (2007). The relationship of previous training and experience of journal peer reviewers to subsequent review quality. PLoS Med, 4(1), 154-156. https://doi.org/10.1371/journal.pmed.0040040

Callaham, M. L., Wears, R. L., \& Waeckerle, J. F. (1998). Effect of attendance at a training session on peer reviewer quality and performance. Annals of Emergency Medicine, 32(3), 318-322. https://doi.org/10.1016/S0196-0644(98)70007-1

Chang, J. J. (2001). Is it worthwhile to pay referees?. Southern Economic Journal, 68(2), 457-463. https://doi.org/10.2307/1061605

Chen, K. (1994). On the uniqueness of the journal. Journal of Intelligent Transportation Systems, 1(4), iii-iv.

Retrieved from https://www.tandfonline.com/doi/citedby/10.1080/10248079408903803?scroll=top\&needAcces s=true. https://doi.org/10.1080/10248079408903803

Committee on Publication Ethics. (2018). Principles of transparency and best practice in scholarly publishing. $\quad$ Retrieved October 15, 2018, from https://publicationethics.org/files/Principles_of_Transparency_and_Best_Practice_in_Scholarly _Publishingv3_0.pdf

Committee on Publication Ethics. (2016). Data sharing. Retrieved October 20, 2018, from https://publicationethics.org/files/u661/Notes\%20from\%20Forum\%20Discussion\%20Topic_12 _February\%202016_DATA_SHARING_final.pdf

Coordenação de Aperfeiçoamento de Pessoal de Nível Superior. (2018). $1^{o}$ encontro CAPES de ciência aberta - Repositórios digitais. Recuperado em 18 de setembro, 2018, de https://youtu.be/Hix3KfyR0OU

Cuellar, N. G. (2018). Recognition for reviewers: PUBLONS!. Journal of Transcultural Nursing, 29(3), 221-221. https://doi.org/10.1177/1043659618764157

Drummond, M. F., \& Jefferson, T. O. (1996). Guidelines for authors and peer reviewers of economic submissions to the BMJ. British Medical Journal, 313(7052), 275-283. https://doi.org/10.1136/bmj.313.7052.275

Fielden, S. L. (2008). Guidelines for reviewers. Gender in Management: An International Journal, 23(1), 7-10.

Kotsis, S. V., \& Chung, K. C. (2014). How to submit a revision and tips on being a good peerreviewer. Plastic and Reconstructive Surgery, 133(4), 958-964. https://doi.org/10.1097/PRS.0000000000000002

Laband, D. N. (1990). Is there value-added from the review process in economics? Preliminary evidence from authors. Quarterly Journal of Economics, 105(2), 341-352. https://doi.org/10.2307/2937790

Lundstrom, K., \& Baker, W. (2009). To give is better than to receive: The benefits of peer review to the reviewer's own writing. Journal of Second Language Writing, 18(1), 30-43. https://doi.org/10.1016/j.jslw.2008.06.002

Mendes-Da-Silva, W. (2018). Editorial: Promoção de transparência e impacto da pesquisa em negócios-editorial. Revista de Administração Contemporânea, 22(4). Recuperado de 
http://www.scielo.br/scielo.php?script=sci_arttext\&pid=S1415-

65552018000400639\&lng=pt\&tlng=pt. https://doi.org/10.1590/1982-7849rac2018180210

Nassi-Calò, L. (2017). In time: Publons seeks to attract reviewers and improve peer review. Revista Paulista de Pediatria, 35(4), 367-368. http://doi.org/10.1590/1984-0462/;2017;35;4;00018

Ortega, J. L. (2017). Are peer-review activities related to reviewer bibliometric performance? A scientometric analysis of Publons. Scientometrics, 112(2), 947-962. https://doi.org/10.1007/s11192-017-2399-6

Ortega, J. L. (2018b). Reliability and accuracy of altmetric providers: a comparison among Altmetric.com, PlumX and Crossref Event Data. Scientrometrics, 116(3), 2123-2138. https://doi.org/10.1007/s11192-018-2838-z

Ortega, J. L. (2018a). The life cycle of altmetric impact: A longitudinal study of six metrics from PlumX. Journal of Informetrics, 12(3), 579-589. https://doi.org/10.1016/j.joi.2018.06.001

Provenzale, J. M. (2010). Revising a manuscript: Ten principles to guide success for publication. American Journal of Roentgenology, 195(6), W382-W387. https://doi.org/10.2214/AJR.10.5553

Rajpert-De Meyts, E., Losito, S., \& Carrell, D. T. (2016). Rewarding peer-review work: The Publons initiative. Andrology, 4(6), 985-986. https://doi.org/10.1111/andr.12301

Smith, D. R. (2016). Will Publons popularize the scientific peer-review process?. BioScience, 66(4), 265-266. https://doi.org/10.1093/biosci/biw010

Staniland, M. (2016, November 4). What makes a great peer reviewer? Tips from Nature Research editors. Retrieved September 29, 2018, from http://blogs.nature.com/ofschemesandmemes/2016/11/04/what-makes-a-great-peer-reviewertips-from-nature-research-editors

Teixeira da Silva, J. A., \& Al-Khatib, A. (2018). The clarivate ${ }^{\mathrm{TM}}$ analytics acquisition of Publons - an evolution or commodification of peer review? Research Ethics. https://doi.org/10.1177/1747016117739941

Verbeke, A., Von Glinow, M. A., \& Luo, Y. (2017). Becoming a great reviewer: Four actionable guidelines. Journal of International Business Studies, 48(1), 1-9. https://doi.org/10.1057/s41267-016-0049-5

\section{Dados do Autor}

Wesley Mendes-Da-Silva

Rua Itapeva, 474, $8^{\circ}$ andar, 01332-000, São Paulo, SP, Brasil.

E-mail: rac.wesley.mendes@gmail.com 